\title{
ANÁLISE MULTITEMPORAL DA DISTRIBUIÇÃO DE MOSCAS SINATRÓPICAS DA FAMÍLIA SARCOPHAGIDAE EM DIFERENTES CONDIÇÕES DE USO DA TERRA NO MUNICÍPIO DE TEODORO SAMPAIO-SP PARA SUBSIDIAR MEDIDAS DE CONTROLE
}

\author{
Leonice Seolin Dias ${ }^{1}$ \\ Rodrigo José Pisani ${ }^{2}$ \\ Raul Borges Guimarães ${ }^{3}$ \\ Rogério Giuffrida ${ }^{4}$ \\ Vamilton Santarém ${ }^{5}$
}

\begin{abstract}
RESUMO
O controle populacional de moscas sinantrópicas em regiões de alta vulnerabilidade social é uma ferramenta inestimável para controle de doenças vetoriadas por esses insetos. O presente trabalho utilizou análises multitemporais para avaliar a distribuição de moscas sinantrópicas da família Sarcophagidae, entre os períodos sazonais do outono, inverno e primavera de 2012 e verão de 2013, em um recorte sobre o município de Teodoro Sampaio, Oeste do estado de São Paulo, Brasil. A região de estudo é caracterizada pelo uso diversificado da terra, com destaque para assentamentos rurais e o Parque Estadual do Morro do Diabo, um dos últimos remanescentes de mata atlântica não litorânea do Estado de São Paulo. Foram colocadas em pontos georreferenciados armadilhas entomológicas compostas de garrafas tipo PET, contendo no interior iscas a base de fígado bovino, em quatros diferentes áreas experimentais: perímetro urbano de Teodoro Sampaio (áreas urbanas), margem da estrada que passa pelo interior do Parque Estadual Morro do Diabo (reserva florestal), assentamentos rurais (assentamentos), e monoculturas de cana-de-açúcar (canavial). Os dados cadastrais foram compostos pelo número de espécimes capturadas da família Sarcophagidae nos pontos georeferenciados. Para elaboração dos mapas de uso da terra e delimitação dos locais das armadilhas foram utilizadas imagens IRS (Indian Research System) com resolução espacial de 24 metros em composição 3R4G5B, pacote computacional ArcGIS 10.2.1 para a elaboração do banco de dados geográficos, cartas topográficas do IBGE em escala 1:50.000 (base cartográfica) e GPS de navegação Garmin para a coleta georreferenciada dos pontos amostrais, onde estavam localizadas as armadilhas entomológicas. Os resultados dispostos em tabelas e mapas ilustraram, de maneira espacializada, a variabilidade das ocorrências notadas principalmente nos períodos de outono,
\end{abstract}

\footnotetext{
${ }^{1}$ Doutoranda em Geografia, FCT/UNESP, Presidente Prudente, SP, nseolin@gmail.com;

2 Pós-doutorando em Medicina Veterinária UNOESTE, Presidente Prudente, SP:

pisanigeo@gmail.com

${ }^{3}$ Docente do Programa de Pós-Graduação em Geografia, FCT/UNESP, Presidente Prudente: raul@fct.unesp.br

${ }^{4}$ Docente do Programa de Mestrado em Ciência Animal, UNOESTE, Presidente Prudente, SP: rgiuffrida@unoeste.br

${ }^{5}$ Docente do Programa de Mestrado em Ciência Animal, UNOESTE, Presidente Prudente, SP: vamilton@unoeste.br
} 
inverno e primavera de 2012. As altas quantidades de moscas, principalmente nas áreas de reserva florestal e nas áreas urbanas, devem-se a provável existência de atrativos para a proliferação de dípteros sinantrópicos, como por exemplo, combinações de temperatura e umidade que favorecem a proliferação dos insetos. A abordagem em SIG mostrou-se eficaz para monitorar populações de moscas e subsidiar políticas de prevenção de doenças vetoriadas por insetos sinantrópicos em áreas de risco.

Palavras-chave: Moscas sinantrópicas, Controle de zoonoses, Sistemas de informações geográficas, Doenças vetoriadas.

\title{
MULTI-TEMPORAL ANALYSIS OF SYNANTHROPIC FLIES (DIPTERA: CALLIPORIDAE) DISTRIBUTION IN DIFFERENT LAND USE CONDITIONS IN MUNICIPALITY OF TEODORO SAMPAIO, SÃO PAULO, BRAZIL
}

\begin{abstract}
Population control of synanthropic flies in areas under high social vulnerability is an important tool for controlling fly-borne transmitted diseases. The present study aimed to evaluate the distribution of flies (Calliphoridae) based on a multi-temporal analysis,including the autumn, winter, springer (2012) and summer (2013) periods, in the municipality of Teodoro Sampaio, Western São Paulo, Brazil. The study area is characterized by diversification of land use, highlighting the high number of settlement rural communities, and the presence of one of the last reminiscent of non-litoreaneus Atlantic Forest of São Paulo, the "Morro do Diabo" State Park. Entomological traps (type PET, containing liver as attractive) were allocated in geo-referenced pointsthat were located in four experimental areas: perimeter of the municipality (urban area); margin of State Park "Morro do Diabo" (forest); rural communities; and sugar cane farm. The database was composed by the number of species collected from Calliphoridar family in georeferencing points. The land use maps and traps delimitation were used orbital images from IRS (Indian Remote Sensing Satellite) with spatial resolution of 24 meters with 3R4G5B composition, software ArcGIS 10.2.1 for geodatabase making, carts from IBGE in 1:50.000 scale and GPS for delimitation and collect data sample. The results showed the variability of ocurrences overall in autum, spring of 2013 and Summer of 2013. The experimental areas where was verified more presence of flies were urban areas and bushes areas (State Park) overall in summer by the warm and moist weather with environment factors of attraction, with lower values for rural communities and sugar cane areas. In conclusion, the multi-temporal analysis may be considered a useful tool for monitoring populations of flies, providing information to be applied for preventing the fly-borne transmitted diseases in risk areas.
\end{abstract}

Key Words: Flies, Zoonoses control, GIS, Vector-borne diseases.

\section{ANÁLISIS VUELA DISTRIBUCIÓN SINANTRÓPICOS FAMILIA MULTITEMPORAL SARCOPHAGIDAE EN DIFERENTES CONDICIONES DE USO DE LA TIERRA DE LA MUNICIPALIDAD DE TEODORO SAMPAIO-SP PARA SUBSIDIAR MEDIDAS DE CONTROL}

\section{RESUMEN}

Control de la población de moscas sinantrópicas en regiones de alta vulnerabilidad social es una herramienta invaluable para control de enfermedades vetoriadas por estos insectos. Este estudio utilizó el análisis multitemporal para evaluar la distribución de moscas sinantrópicas de la familia Sarcophagidae, entre los periodos de temporada de otoño, invierno y la primavera de 2012 y el 


\section{Periódica Eletrânica \\ Fórum Ambiental}

da Alta Paulista
Volume 11, Número 08, 2015

Saúde e Saneamento Ambiental

verano de 2013 en un recorte en la ciudad de Teodoro Sampaio, estado de São Paulo, Brasil. El área de estudio se caracteriza por el uso diverso del suelo, sobre todo en los asentamientos rurales y el Parque Estatal de Morro do Diabo, uno de los últimos bosques tropicales no costeros restante en el Estado de São Paulo. Fueron colocados en puntos georreferenciados trampas entomológicas compostas de botellas de PET que contiene dentro de elas cebos con hígado de res, en cuatro zonas experimentales diferentes: perímetro urbano de Teodoro Sampaio (zonas urbanas), borda de la carretera que pasa por el interior del Parque Estatal Morro Diablo (reserva forestal), asentamientos rurales (asentamientos), y los monocultivos de caña de azúcar (caña). Los datos de registro fueron compuestos por el número de ejemplares capturados de la familia Sarcophagidae en puntos georeferenciados. Para la preparación de los mapas de uso del suelo y la delimitación de los locales de las trampas se utilizaron imágenes del IRS (Indian Research System) con una resolución espacial de 24 metros en la composición 3R4G5B, paquete computacional ArcGIS 10.2.1 para la preparación de la base de datos geográfica, mapas topográficos de el IBGE escala de 1: 50.000 (mapa base) y GPS de navegación Garmin para la recogida georeferenciada de puntos de muestra, donde se encuentran las trampas entomológicas. Los resultados mostrados en tablas y mapas ilustraram, de forma espacializada, la variabilidad de las ocurrencias observadas principalmente durante el otoño, el invierno y la primavera de 2012. Las altas cantidades de moscas, en especial en las áreas de reserva forestal y de las zonas urbanas, se deben a la probable existencia de apelar a la proliferación de moscas sinantrópicas, como combinaciones de temperatura y humedad que favorecen la proliferación de insectos. El enfoque de SIG fue eficaz para controlar las poblaciones de moscas y subsidiar políticas de prevención de enfermedades vetoriadas por las moscas sinantrópicas en áreas peligrosas.

Palabras clave: Moscas sinantrópicas, Control de zoonosis, Sistemas de información geográfica, Enfermedades vetoriadas.

\section{INTRODUÇÃO}

As proliferações de moscas sinantrópicas representam importante problema de saúde pública, com altos custos financeiros que poderiam ser minimizados com adoção de políticas de planejamento, com caráter preventivo.

Em áreas onde ocorrem grandes acúmulos de dejetos orgânicos existe a atração e proliferação de grande número de muscídeos sinantrópicos, que se contaminam com micro-organismos patogênicos e, por sua vez, dispersam bactérias como, Salmonella e E. coli, ao se deslocarem para as cidades, tornando-se grave problema de saúde pública. Além do problema nas cidades, moscas provenientes de áreas com acúmulo de dejetos podem dispersar-se para as áreas de mata nativa, onde ameaçam a fauna com a disseminação dos agentes já citados.

Uma das etapas para uma política de prevenção é o monitoramento do aumento da população e densidade de moscas, visando modelar e mapear para quais áreas especificamente as moscas se dispersam em diferentes épocas do ano e, em quais locais se concentram, buscando possível explicação para esse 
fenômeno espacial a fim de predizer áreas com alta ou baixa propensão para o risco de doenças vetoriadas por esses insetos.

O objetivo do presente trabalho foi o de verificar ao longo do ano de 2012, nas estações de outono, inverno, primavera e verão 2012/2013, a distribuição e incidência de moscas da família Sarcophagidae em diferentes estações experimentais, a fim de estabelecer em quais áreas e épocas existem maiores concentrações de insetos para fins de monitoramento e prevenção de riscos de doenças relacionadas a vetores de agentes infecciosos.

\section{REVISÃO DE LITERATURA}

Os dípteros constituem uma das maiores populações de insetos cosmopolitas, adaptando-se a vários nichos e diferentes habitats (PAPE; BICKEL; MEIER, 2009). Dentre as espécies de dipteros sinantrópicos, destacam-se as moscas das famílias Muscidae, Fannidae, Sarcophagidae e Calliphoridae, reconhecidas como vetores mecânicos de diversas enfermidades infecto-parasitárias (GRACZYK et al., 2001).

Moscas sinantrópicas habitualmente utilizam substratos orgânicos para sua reprodução e alimentação, notadamente dejetos humanos, de animais e matéria orgânica em decomposição, o que aumenta a probabilidade de portarem microorganismos entéricos responsáveis por gastrenterites infecciosas em humanos e animais (LEVINE; LEVINE, 1991). Os locais anatômicos mais contaminados são as o exoesqueleto de quitina, a proboscida (aparelho sugador), patas e tubo alimentar (NAZNI et al., 2005).

As pernas das moscas são porções corpóreas que facilmente se contaminam com agentes infecciosos, em razão de conterem pelos extremamente finos e circundados por substâncias aderentes que Ihes permite caminhar em superfícies não-horizontais e retenção de agentes infecciosos e parasitários (SUKONTASON et al., 2000). Substratos viscosos como as fezes favorecem a adesão de microrganismos fecais nas patas e exoesqueleto desses insetos (GRACZYK et al., 1999).

Moscas sinantrópicas proliferam excessivamente em ambientes de condições higiênico-sanitárias precárias (NMORSI; AGBOZELE; UKWANDU, 2007). Nesses ambientes, o controle populacional de moscas é associado a reduções significativas 
na incidência de casos de diarreia em humanos causadas por Shigella spp e Escherichia coli (COHEN et al., 1991). Em ambientes próximos a hospitais, moscas sinantrópicas tendem à carrear agentes patogênicos multirresistentes frente à antimicrobianos de uso corrente (RAHUMA et al., 2005).

A íntima associação entre a qualidade ambiental e a presença de moscas sinantrópicas as qualifica como bioindicadores fidedignos da qualidade ambiental de uma área, visto que a densidade populacional e diversidade de espécies desses insetos tende a elevar-se em áreas consideradas insalubres (ADEYEMI; DIPEOLU, 1984).

A família Sarcophagidae agrega espécies que se proliferam predominantemente em cadáveres em decomposição e que têm importância em entomologia forense (CARVALHO; MELLO-PATIU, 2008). Esses insetos, comumente conhecidos como "moscas-da-carne", são moscas não hematófagas, de distribuição cosmopolita. Os adultos, geralmente, são moscas robustas e de tamanho médio a grande (de 5 a $20 \mathrm{~mm}$ ), de coloração acinzentada e com a presença de três listras longitudinais escuras no tórax e abdome axadrezado (preto e prata) (LOPES, 1973; MELLO-PATIU; SOARES; SILVA, 2009; PAPE et al., 2012) (Figura 1).

FIGURA 1: Exemplo de mosca da família Sarcophagidae

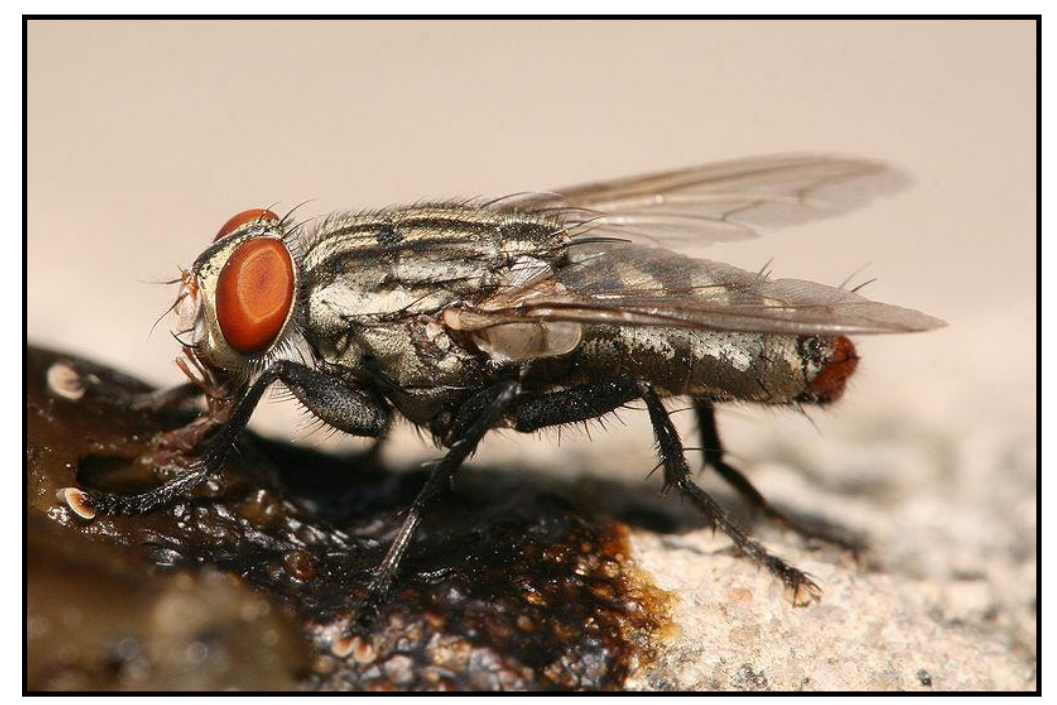

Fonte: https://en.wikipedia.org/wiki/File:Sarcophaga_Bercaea2.jpg

As larvas de sarcofagídeos podem desenvolver-se em vários tipos de substratos em áreas rurais e urbanas, como em matéria orgânica animal em 
decomposição, incluindo também esterco, restos de vegetais e fezes; mas, geralmente, preferem os estágios adiantados de decomposição de cadáveres humanos e de animais domésticos. Desta forma, são reconhecidamente também elementos importantes na decomposição de carcaças e na reciclagem de nutrientes no ecossistema (MARCHENKO, 1985; BYRD; CASTNER, 2001; MARCHIORI et al., 2003).

O controle dessas moscas, como das moscas domésticas, não tarefa fácil, e o uso de inseticidas químicos tem sido o mais comum para conter suas populações. Como a utilização de produtos químicos contamina o meio ambiente e os alimentos, então, o correto controle desses insetos seria diminuir as principais fontes de alimentação e reprodução. Além disso, segundo Lindsay e Scudder (1956) e Shimizu et al., (1965), a presença e a quantidade de moscas em um determinado local podem ser utilizadas como bioindicadores de condições sanitárias, uma vez que a veiculação de patógenos por moscas é dependente das más condições sanitárias.

\section{MATERIAIS E MÉTODOS}

\section{Caracterização da área de estudo:}

A área de estudo está localizada no município de Teodoro Sampaio-SP, que possui uma população de aproximadamente 21.395 habitantes (IBGE, 2010) e distante aproximadamente $670 \mathrm{~km}$ da capital São Paulo. Entre as áreas de uso e cobertura da terra destacam-se classes de pastagens, culturas agrícolas (principalmente cana-de-açúcar), área urbana e remanescentes de mata nativa, com destaque para o Parque Estadual do Morro do Diabo, que representa um dos últimos remanescentes de mata atlântica do Estado de São Paulo, conforme ilustra a Figura 2 e 3 . 
FIGURA 2. Localização da área de estudo.

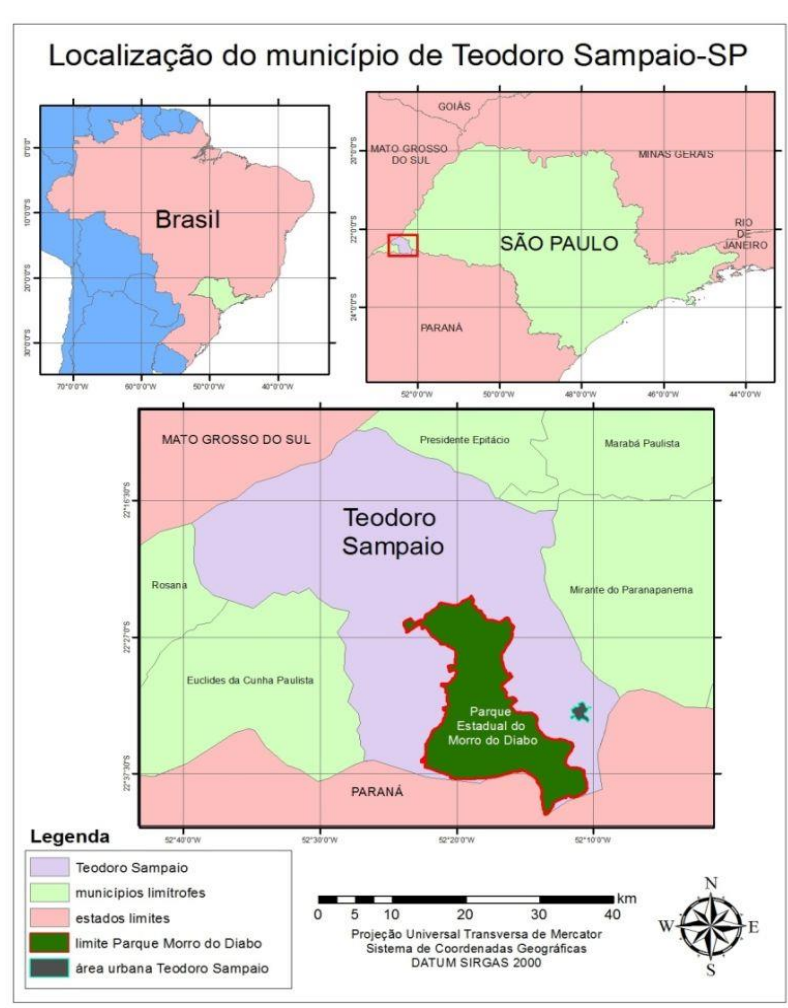

Organização: Pisani (2014).

FIGURA 3. Localização da área de estudo com ênfase nas áreas de uso e cobertura da terra.

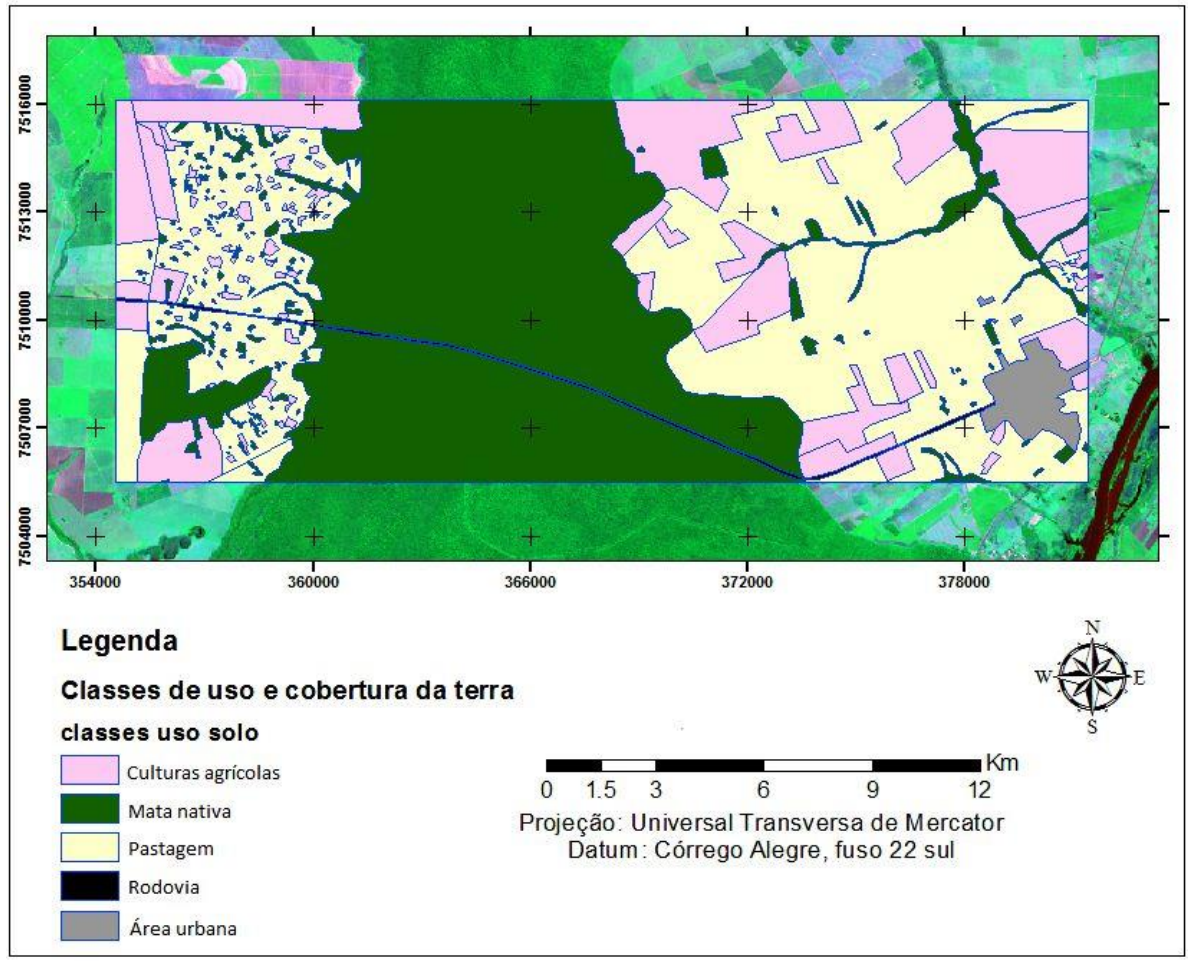




\section{Elaboração da base cartográfica e captura e das moscas}

Para a elaboração do mapa de uso e cobertura da terra, foi utilizada uma imagem orbital de 14 de julho de 2013, órbita 326, ponto 094, obtida a partir do satélite IRS P6 (Indian Remote Sensing/Resourcesat-1) sensor LISS III (Linear Imaging Self-Scanner), a partir do cadastro gratuito de imagens do site do INPE (Instituto Nacional de Pesquisas Espaciais) www.inpe.br que, posteriormente, foi registrada com base na carta do IBGE (Instituto Brasileiro de Geografia e Estatística) utilizada para a pesquisa da área de estudo em escala de 1:50.000 a partir do método de anexação das coordenadas do cruzamento das quadrículas da carta topográfica para o projeto de trabalho. O Datum utilizado foi o Córrego Alegre, fuso 22 sul. Foram consideradas as seguintes áreas experimentais para o presente estudo: 1 - Área urbana; 2 - Assentamento; 3 - Canavial; 4 - Reserva Florestal.

A interpretação das imagens para a obtenção dos mapas das áreas experimentais foi realizada por meio da técnica de interpretação visual a partir da rotulação de polígonos no programa ArcGIS 10.2.1 (ESRI, 2010) com validação dos dados em campo. Para uma melhor análise visual e rotulação dos polígonos, a imagem utilizada foi contrastada, utilizando-se uma função linear. As bandas utilizadas foram 3 (vermelho), 4 (infravermelho próximo) e 5 (infravermelho médio). Depois de contrastadas, foi gerada uma composição colorida no ArcGIS (função composite bands) que foi utilizada como base das interpretações pela técnica de vetorização de polígonos. Ressalta-se que este método é baseado inteiramente na experiência do analista, o qual extrai as informações de uso e cobertura da terra com base nas características das imagens como: textura, forma, tamanho e padrões, além das informações obtidas no campo. A Figura 4 ilustra o mapa das áreas experimentais. 
FIGURA 4. Áreas experimentais selecionadas para o presente estudo.

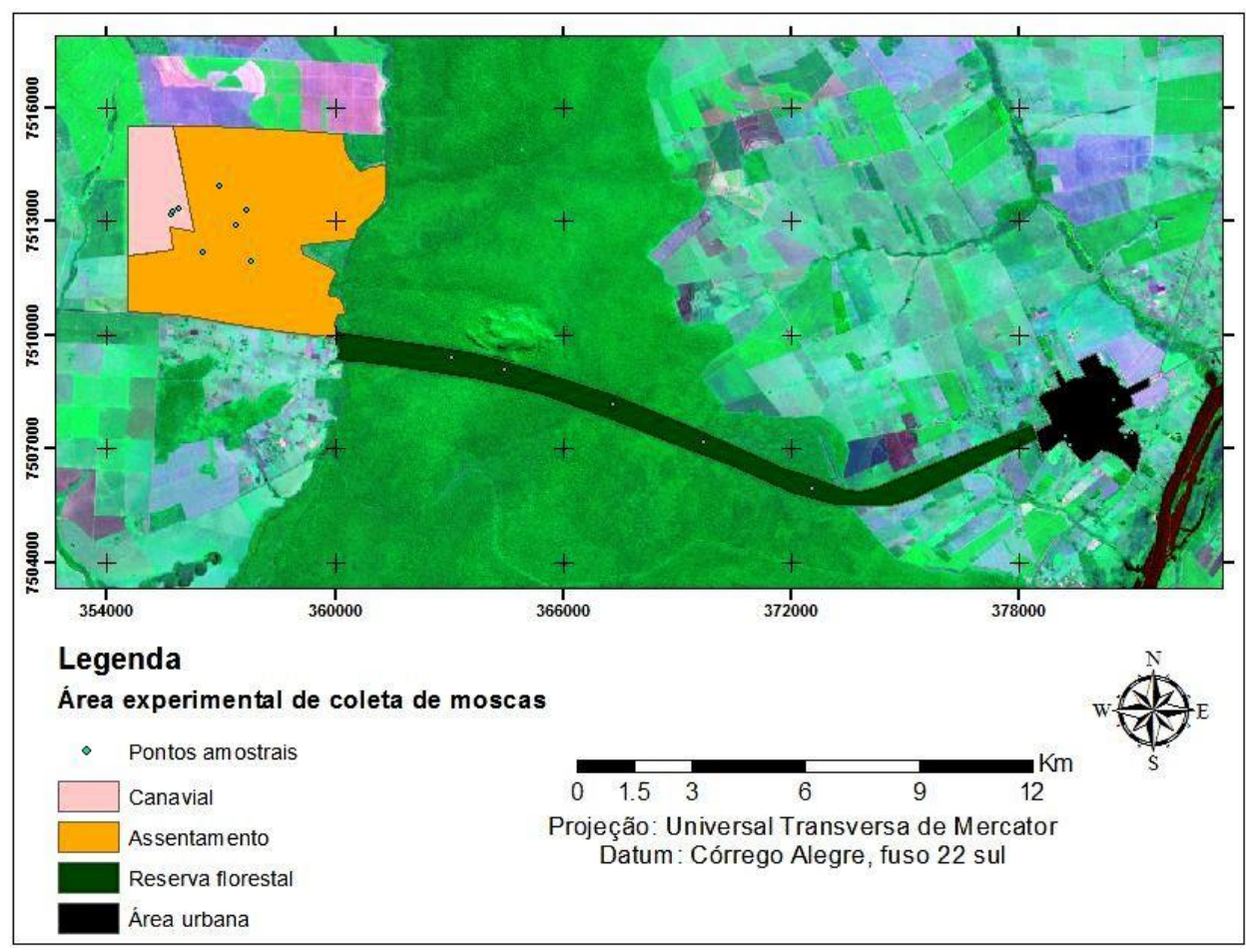

Organização: Pisani (2014).

Para a captura das moscas, foram utilizadas armadilhas entomológicas compostas por duas garrafas tipo PET encaixadas uma sobre a outra, contendo iscas a base de fígado penduradas em ganchos metálicos no interior da garrafa interna (DIAS et al., 2009). Antes do uso, as armadilhas empregadas foram pintadas de preto a fim de evitar a atração diferenciada pela cor, desinfetadas com álcool $70 \%$ e seladas com fita adesiva e papel estéril (FERRAZ; AGUIAR-COELHO, 2008). Como parte do procedimento de amostragem, todos os pontos de coleta de armadilhas foram georreferenciados a partir de obtenção dos dados de coordenadas planas em UTM (Universal Transversa de Mercator) em X e Y com o número de moscas coletadas.

Após a captura, as armadilhas foram removidas e as moscas foram submetidas a congelamento em freezer na temperatura de $-20^{\circ} \mathrm{C}$ para inativação e encaminhadas para o laboratório de identificação no menor tempo possível. Posteriormente ao separar-se as moscas pela similaridade física em placas de Petri estéreis, as famílias taxonômicas foram identificadas com auxílio de lupa e sistemas de classificação morfológica específicos para cada grupo (CARVALHO; MELLO-PATIU, 2008). 


\section{RESULTADOS E DISCUSSÕES}

Por meio das coletas nas armadilhas foram possíveis a identificação e quantificação da incidência de moscas coletadas em diferentes regiões experimentais da área de estudo. A figura 4 ilustra os mapas com as incidências das moscas em diferentes períodos sazonais em cada região experimental. A quantificação dos insetos está contida na Tabela 1.

FIGURA 5. Mapas com diferentes concentrações de moscas em diferentes períodos sazonais e em cada região experimental.
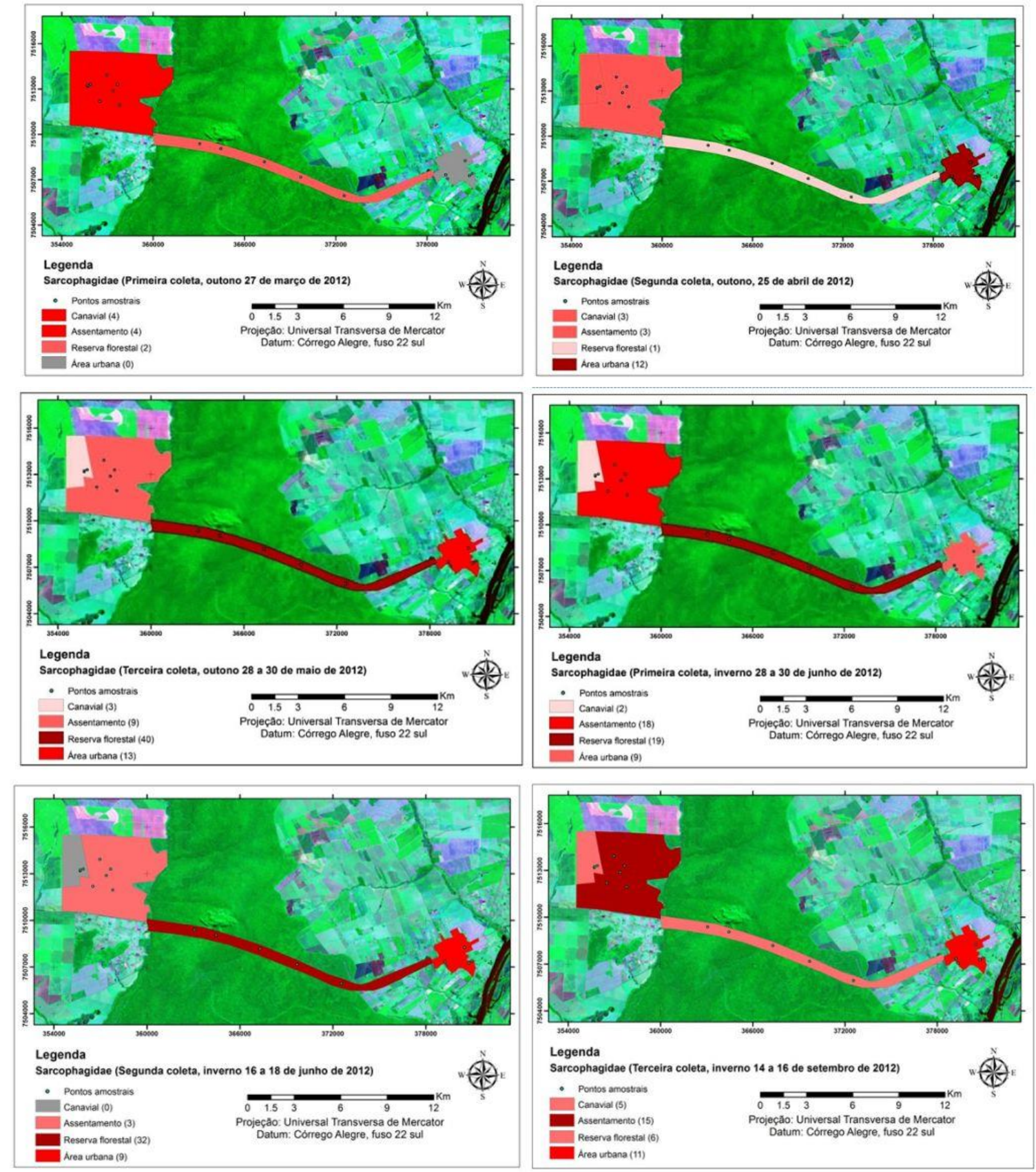

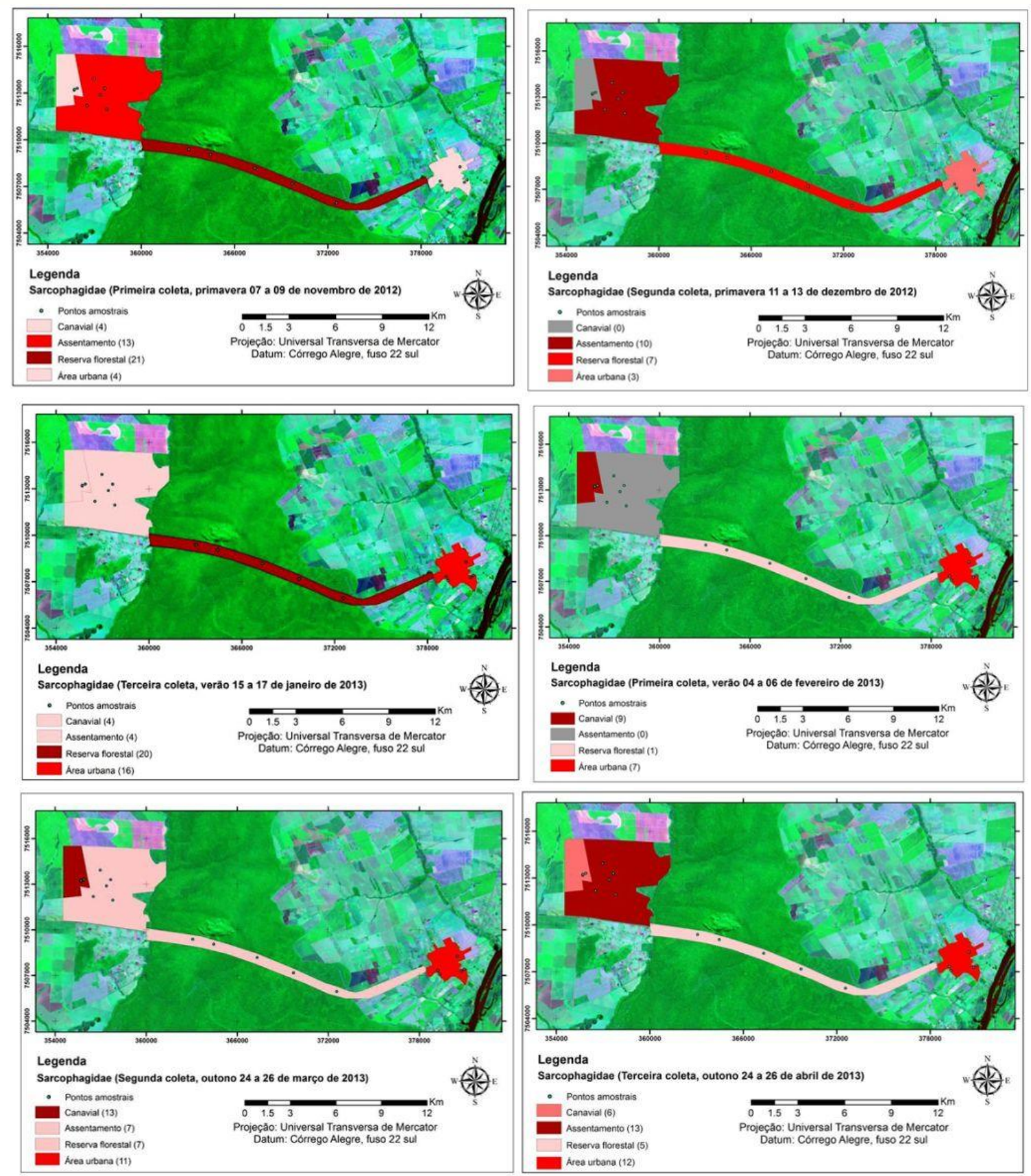

Organização: Pisani (2015). 
TABELA 1. Número de moscas identificadas em diferentes épocas do ano e em áreas experimentais.

\begin{tabular}{|c|c|c|c|c|c|c|c|c|c|c|c|c|}
\hline & \multicolumn{3}{|c|}{ Outono 2012} & \multicolumn{3}{|c|}{ Inverno 2012} & \multicolumn{3}{|c|}{ Primavera 2012} & \multicolumn{3}{|c|}{ Verão/outono 2013} \\
\hline Coleta & $1^{\text {a }}$ & $2^{\mathrm{a}}$ & $3^{\text {a }}$ & $1^{\underline{a}}$ & $2^{\mathrm{a}}$ & $3^{\mathrm{a}}$ & $1^{\mathrm{a}}$ & $2^{\mathrm{a}}$ & $3^{\mathrm{a}}$ & $1^{\mathrm{a}}$ & $2^{\mathrm{a}}$ & $3^{\mathrm{a}}$ \\
\hline Área urbana & 0 & 12 & 13 & 9 & 9 & 11 & 4 & 3 & 16 & 7 & 11 & 12 \\
\hline $\begin{array}{l}\text { Reserva } \\
\text { Florestal }\end{array}$ & 2 & 1 & 40 & 19 & 32 & 6 & 21 & 7 & 20 & 1 & 7 & 5 \\
\hline Assentamento & 4 & 3 & 9 & 18 & 3 & 15 & 13 & 10 & 4 & 0 & 7 & 13 \\
\hline Canavial & 4 & 3 & 3 & 2 & 0 & 5 & 4 & 0 & 4 & 9 & 13 & 6 \\
\hline Total & 10 & 19 & 65 & 48 & 44 & 37 & 42 & 20 & 44 & 17 & 38 & 36 \\
\hline $\begin{array}{c}\text { Total } \\
\text { estações }\end{array}$ & & 94 & & & 129 & & & 10 & & & 9 & \\
\hline
\end{tabular}

A maior incidência de moscas deu-se entre os períodos do final do outono de 2012, com grande incidência no inverno e uma gradual diminuição dos índices na primavera de 2012 e verão/outono de 2013.

As áreas experimentais onde mais se verificaram as ocorrências foram as regiões de reserva florestal e áreas urbanas. Os assentamentos rurais e canaviais foram as classes que menos apresentaram incidências no decorrer dos períodos analisados. Uma das hipóteses prováveis é que houve nesse período uma combinação de elementos como temperatura e umidade que favoreceram a proliferação das moscas nas regiões de borda da reserva florestal, diferentemente do esperado que seria nos períodos de verão, onde provavelmente as altas temperaturas, aliadas a pluviosidades menos pronunciadas para o período, inibiram a eclosão e, consequentemente, a proliferação de moscas Sarcophagidae. Ademais, nas zonas florestais populações residentes de animais silvestres podem proporcionar substratos para proliferação de sarcogafídeos, insetos carcaterizados pela larviposição em cadáveres.

Esperava-se que as maiores incidências de moscas estivessem nas áreas urbanas pelas condições reinantes caracterizadas pela disponibilidade de substratos orgânicos para os insetos sinantrópicos. Porém, foram nas áreas de reserva florestal que as moscas da família Sarcophagidae mais se proliferaram, mostrando assim uma tendência marcante dessa família de moscas na região. 


\section{CONCLUSÕES}

As áreas de florestas e o centro urbano foram os de maior incidência de insetos, e os assentamentos rurais e os canaviais os de menor.

Apesar das áreas urbanas terem ficado em segundo lugar, não se deve excluir a situação de alerta para o risco de doenças vetoriadas por insetos, que podem ocorrer para a população local do município e também, em contato com as áreas de borda da reserva florestal, para a fauna local, mostrando com isso uma situação de risco a se levar em consideração.

\section{REFERÊNCIAS}

ADEYEMI, O.; DIPEOLU, O. O. The numbers and varieties of bacteria carried by filth flies in sanitary and unsanitary city area. International journal of zoonoses, v. 11, n. 2, p. 195-203, dez. 1984.

BARRO, N. et al. Carriage of bacteria by proboscises, legs, and feces of two species of flies in street food vending sites in Ouagadougou, Burkina Faso. Journal of food protection, v. 69, n. 8, p. 200710, ago. 2006.

CARVALHO, C. J. B. DE; MELLO-PATIU, C. A. Key to the adults of the most common forensic species of Diptera in South America. Revista Brasileira de Entomologia, v. 52, n. 3, p. 390-406, set. 2008.

COOKE, E. A.; O'NEILL, G.; ANDERSON, M. The survival of ingested Serratia marcescens in houseflies (Musca domestica L.) after electrocution with electric fly killers. Current microbiology, v. 46, n. 2, p. 151-3, fev. 2003.

ESRI - ENVIRONMENTAL SYSTEM RESEARCH INSTITUTE. ARC/INFO v.10 Redlands, 2010. Programa de computador. DVD-ROM.

GRACZYK, T. K. et al. The role of non-biting flies in the epidemiology of human infectious diseases. Microbes and infection / Institut Pasteur, v. 3, n. 3, p. 231-5, mar. 2001.

GRACZYK, T. K. et al. House flies (Musca domestica) as transport hosts of Cryptosporidium parvum. The American journal of tropical medicine and hygiene, v. 61, n. 3, p. 500-4, set. 1999.

IBGE. Instituto Brasileiro de Geografia e Estatística. Censo Demográfico 2010. Rio de Janeiro: IBGE. 2010. Disponível em: http://cidades.ibge.gov.br/xtras/perfil.php. Acesso em 04 dez. 2013.

LEVINE, O. S.; LEVINE, M. M. Houseflies (Musca domestica) as mechanical vectors of shigellosis. Reviews of infectious diseases, v. 13, n. 4, p. 688-96, 1991.

MCGONIGLE, D. F.; JACKSON, C. W. Effect of surface material on electrostatic charging of houseflies (Musca domestica L). Pest management science, v. 58, n. 4, p. 374-80, abr. 2002.

NAZNI, W. A. et al. Bacteria fauna from the house fly, Musca domestica (L.). Tropical biomedicine, v. 22, n. 2, p. 225-31, dez. 2005.

PAPE, T.; BICKEL, D. J.; MEIER, R. Díptera Diversity: Status, Challenges and Tools. Leiden: BRILL ACADEMIC PUB, 2009. 459 p. 
PETRIDIS, M. et al. Horizontal transfer of Shiga toxin and antibiotic resistance genes among Escherichia coli strains in house fly (Díptera: Muscidae) gut. Journal of medical entomology, v. 43, n. 2, p. 288-95, mar. 2006.

RAHUMA, N. et al. Carriage by the housefly (Musca domestica) of multiple-antibiotic-resistant bacteria that are potentially pathogenic to humans, in hospital and other urban environments in Misurata, Libya. Annals of tropical medicine and parasitology, v. 99, n. 8, p. 795-802, dez. 2005.

SUKONTASON, K. et al. Mechanical carrier of bacterial enteric pathogens by Chrysomya megacephala (Diptera: Calliphoridae) in Chiang Mai, Thailand. The Southeast Asian journal of tropical medicine and public health, v. 31 Suppl 1, p. 157-61, jan. 2000. 